\title{
Greetings from the Director
}

In April 2008, Otsuma Women’s University’s Institute of Human Living Sciences was rechristened the Institute of Human Culture Studies. The former Institute had worked with the Graduate School of Home Economics for almost a quarter century, conducting scientific inquiries on all aspects of human life and nurturing young researchers. With the beginning of the 21st century, the new Institute will have a new role, becoming the core of Otsuma Women's University's research structure and a fundamental support for to the new Graduate School of Studies in Human Culture.

In order to build a harmonious society where individuals can lead full and satisfying lives, we must use our wisdom to overcome the myriad problems and illnesses that confront us.

To this end, the Institute of Human Culture Studies will strive to create an alliance of experts, from within and without the university, that will develop a new "Study of Human Living", a field that transcends divisions between the natural sciences, sociology, and the humanities.

The Institute of Human Culture Studies has several distinct strengths: 1) We are part of Otsuma Women's University, an institution with over a century of history. 2) We are based in Tokyo, a global center of information exchange. 3) Our university conducts research in such fields as Home Economics, Language and Literature, Human Relations, Social Information Studies, and Comparative Culture. The Institute's mission is to utilize these strengths; we have already begun focusing our research efforts along the following objectives:

1) Create a new, interdisciplinary "Study of Human Living"

2) Promote joint research program among industrial, academic and governmental organizations

3) Promote international exchange and contribute to the global community

4) Support the training of young researchers

5) Develop and promote new research to benefit women through collaboration with both academic and lay organizations and individuals

6) Collect and compile research and research support materials and distribute them in an easy-to-use format

Under the banner of "the wisdom and science of living”, it is our hope to tackle new challenges facing our society. Our sincere thanks for your continued understanding and support of the Institute of Human Culture Studies.

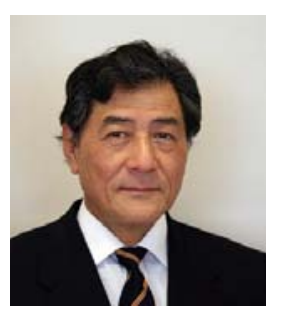

Seiji Ohsawa, $\mathrm{PhD}$,

Director, Institute of Human Culture Studies

Otsuma Women's University 